\title{
Comunicação
}

[Communication]

\section{Doença granulomatosa sistêmica em bovinos no estado de Santa Catarina associada ao pastoreio de ervilhaca peluda (Vicia villosa)}

\author{
[Systemic granulomatous disease in cattle in Santa Catarina, Brazil, associated with \\ grazing of vetch (Vicia villosa)] \\ R.E. Mendes ${ }^{1}$, V.Surkamp ${ }^{2}$, D.C. Machado ${ }^{3}$, C. Pilati $^{4}$ \\ ${ }^{1}$ Centro Universitário Barriga Verde - UNIBAVE \\ ${ }^{2}$ Veterinário Autônomo \\ ${ }^{3}$ Universidade do Contestado - UNC \\ ${ }^{4}$ Universidade do Estado de Santa Catarina - UDESC
}

A utilização de ervilhaca comum (Vicia sativa) associada a outras pastagens de inverno é comum no estado de Santa Catarina, e sua consorciação é recomendada pela alta produção de matéria vegetal e acúmulo de nitrogênio (Heinrichs e Fancelli, 1999). Entretanto, nos últimos anos, foi observada uma crescente contaminação desta com sementes de Vicia villosa.

Casos de intoxicação por ervilhaca têm sido descritos no país. Rissi et al. (2007) relataram a ocorrência de sete casos durante os anos de 1990 e 2005, totalizando $1,5 \%$ dos casos de intoxicação por plantas no Rio Grande do Sul em bovinos. A forma mais comum de apresentação desta intoxicação é uma dermatite acompanhada de doença granulomatosa sistêmica, com morbidade entre 1 e $68 \%$ e mortalidade entre 50 e 100\% (Panciera et al., 1992; Fighera e Barros, 2004). As lesões de pele associadas à forma granulomatosa da intoxicação por ervilhaca variam com o estágio da doença e incluem dermatite papular, ulcerativa ou exsudativa (Odrizola et al., 1991; Harper et al., 1993), espessamento cutâneo e, por fim, alopecia (Odrizola et al., 1991; Fighera et al., 2005).

O objetivo deste trabalho foi descrever dois casos de intoxicação espontânea por ingestão de pastagem contaminada por ervilhaca peluda (Vicia villosa) no planalto norte de Santa Catarina, em vacas da raça Holandesa e cruzadas Holandês e Jersey.

Recebido em 18 de março de 2011

Aceito em 12 de julho de 2011

E-mail: z62memer@uco.es
Os dados epidemiológicos e clínicos foram obtidos durante visita às propriedades. Foi realizada a necropsia nos três animais afetados. Fragmentos de vários tecidos foram coletados, fixados em formol tamponado a $10 \%$, processados rotineiramente e corados com hematoxilina e eosina. Em ambos os casos, as propriedades estavam destinadas à bovinocultura de leite, e os animais estavam em pastejo direto de aveia preta (10-20\%) e azevém (20-30\%), contaminadas com ervilhaca peluda (50-70\%) (Fig. 1A). Os animais recebiam 5kg/dia/animal de concentrado, composto por milho, farelo de trigo e soja.

Os surtos ocorreram nos meses de agosto e setembro, no momento de maior crescimento da pastagem. Na propriedade 1 , adoeceram dois animais de um total de 70 existentes $(2,9 \%$ do rebanho), e na propriedade 2 adoeceu um animal entre $8(12,5 \%)$, todos com cinco anos de idade ou mais e em pico de lactação. Os sinais clínicos iniciaram entre oito e 10 dias após o início do pastejo. Todos os três animais morreram devido à intoxicação.

Os sinais clínicos foram anorexia, diminuição na produção láctea, perda de peso, hipertermia $\left(40,5^{\circ} \mathrm{C}\right)$, áreas alopécicas distribuídas por todo o corpo, as quais se tornaram crostosas após cinco dias de evolução (Fig. 1B), com distribuição irregular, formato não definido, e tamanho variando de $2 \mathrm{~mm}$ até $10 \mathrm{~cm}$. Ainda, os animais mostravam-se agitados e com intenso prurido. 
Também, como lesões macroscópicas, foi observado aumento acentuado e generalizado dos linfonodos, que na superfície de corte apresentavam perda de diferenciação entre a cortical e a medular, e nódulos esbranquiçados de 1 a $5 \mathrm{~cm}$ (Fig. 1C). Os rins estavam aumentados e com nódulos esbranquiçados, tanto na superfície capsular quanto ao corte, de $2 \mathrm{~mm}$ até $2 \mathrm{~cm}$ (Fig. 1D), e, também, edema pulmonar intersticial leve difuso, fígado levemente amarelado de distribuição difusa e adrenais aumentadas.

Microscopicamente, os rins apresentaram infiltrado inflamatório granulumatoso multifocal moderado a severo (Fig. 1E), com presença moderada de cilindros hialinos na luz de túbulos. Em glândulas adrenais, íleo e omaso, observouse infiltrado granulomatoso moderado difuso, assim como em glândula mamária, a qual apresentava também grande quantidade de corpora amilacea na luz de tubos. No sistema nervoso central, foi observado infiltrado inflamatório de linfócitos perivascular leve difuso, nos linfonodos infiltrado granulomatoso moderado a severo multifocal, e nos pulmões infiltrado inflamatório de neutrófilos em bronquíolos e alvéolos localizados na região distal dos lóbulos apicais, associado a leve infiltrado granulomatoso intersticial. Ainda: infiltrado inflamatório granulomatoso difuso na derme superficial, associado à hiperqueratinização da epiderme, formação de crostas multifocais, perifoliculite granulomatosa, edema moderado na derme superficial $\mathrm{e}$ incontinência pigmentaria. O fígado apresentouse com degeneração vacuolar moderada centro e médio lobular e leve infiltrado mononuclear multifocal. $\mathrm{O}$ infiltrado inflamatório granulomatoso estava constituído, predominantemente, por macrófagos epitelioides, linfócitos, plasmócitos, alguns eosinófilos e ocasionais células gigantes multinucleadas na derme e nos rins.

O gânglio nervoso trigeminal apresentou um infiltrado inflamatório granulomatoso, composto por macrófagos epitelioides e linfócitos sem a presença de células gigantes multinucleadas. Lesões semelhantes foram descritas por Reck et al. (2004) no encéfalo de bovinos.

Os sinais clínicos e as lesões anatomopatológicas observados nestes dois casos são similares aos já descritos na literatura (Johnson et al., 1992; Panciera et al., 1992; Barros et al., 2001; Fighera e Barros, 2004; Reck et al., 2004; Fighera et al., 2005).

No diagnóstico diferencial desta enfermidade, deve-se incluir a intoxicação por polpa cítrica, já descrita no Brasil, e que apresenta lesões similares às descritas neste estudo, além de hemorragias (Gava e Barros, 2001). Ainda, devese levar em conta uma enfermidade com lesões também muito similares, descrita na Europa, e ocasionada pela ingestão de diferentes produtos químicos, em geral presentes na alimentação, e que normalmente ocorre no inverno, denominada síndrome de prurido, pirexia e hemorragia (Matthews e Shreeve, 1978; Breukink et al., 1978). Entretanto, uma investigação epidemiológica possibilita um diagnostico definitivo. As lesões semelhantes entre estas doenças propõem, como agente causal, diferentes substâncias químicas com ação similar, uma reação de hipersensibilidade tipo IV; todavia, o mecanismo de ação destas ainda não está estabelecido.

Palavras-chave: envenenamento, Vicia spp., inflamação granulomatosa, patologia 

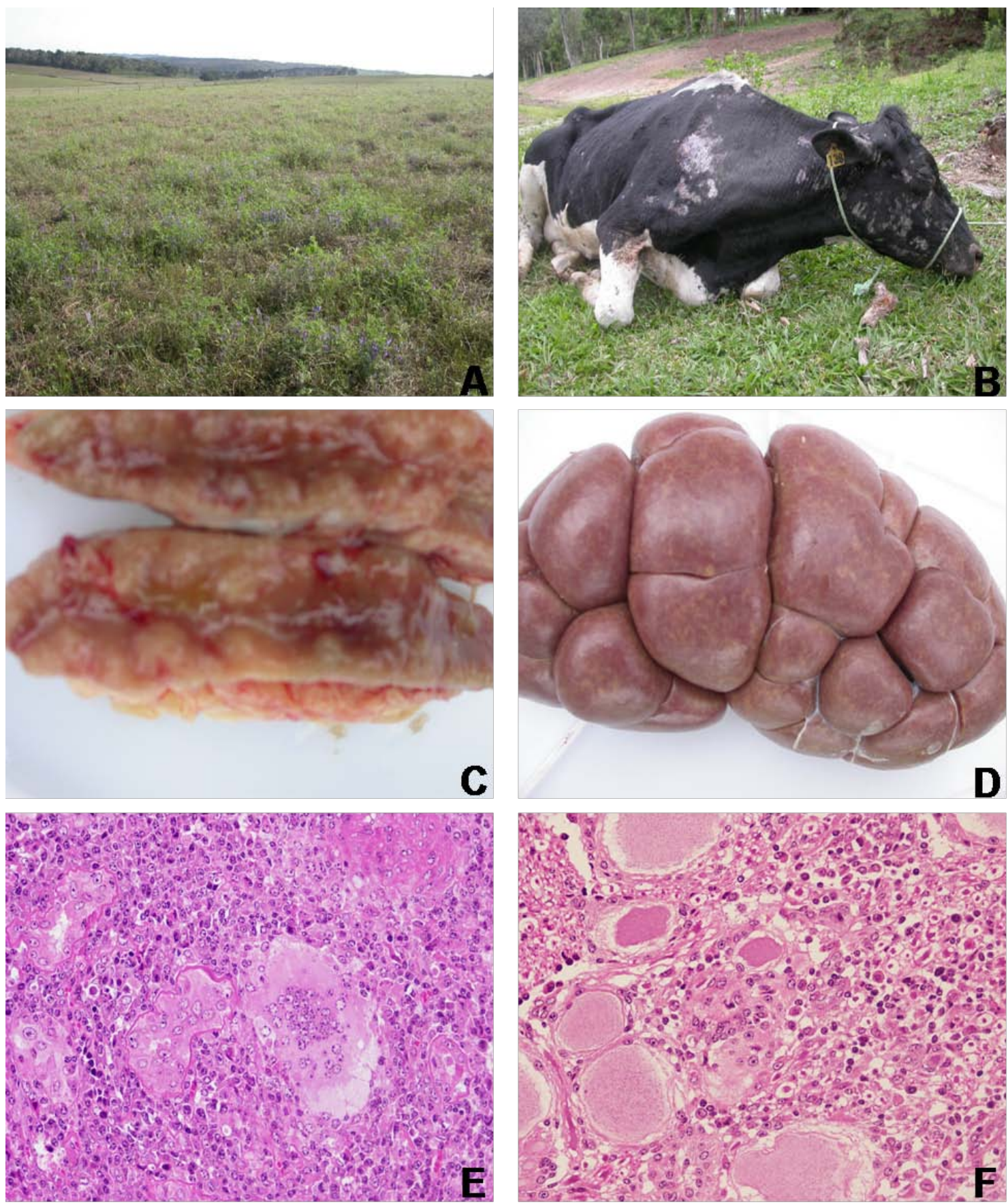

Figura 1. Bovino. A) Aspecto da lavoura com predomínio de Vicia villosa em relação à Avena sativa e Lolium perenne. B) Áreas alopécicas na cabeça e pescoço, algumas apresentando crostas. C) Linfonodo, nódulos multifocais sobressaindo da superfície de corte na região cortical de até $2 \mathrm{~cm}$. D) Rim, aumentado de tamanho, numerosos nódulos branco-acinzentados na superfície capsular de até 0,5cm. E) Rim, infiltrado inflamatório granulomatoso severo difuso, composto por macrófagos epitelioides, linfócitos, plasmócitos e células gigantes multinucleadas. H\&E, Obj. 40x. F) Gânglio nervoso trigeminal, infiltrado inflamatório granulomatoso moderado multifocal, composto por macrófagos epitelioides, linfócitos e plasmócitos. H\&E, Obj. 40x. 


\begin{abstract}
Spontaneous intoxication in three dairy cows grazing pasture contaminated with Vicia villosa in two different farms was reported. Hyperthermia, skin alopecia and pruritus were the main clinical signs. Macroscopically, gray to white up to $5 \mathrm{~cm}$ nodules were detected, especially in kidney and lymph nodes, which correspond to mild to severe multifocal granulomatous infiltrate. This is the first report of systemic granulomatous disease due to consumption of hairy vetch in the State of Santa Catarina, Brazil.
\end{abstract}

Keywords: poisoning plant, Vicia spp., granulomatous inflammation, pathology

\section{REFERÊNCIAS BIBLIOGRÁFICAS}

BARROS, C.S.L.; FIGHERA, R.A.; ROSA, D.B. et al. Doença granulomatosa sistêmica em bovinos no Rio Grande do Sul associada ao pastoreio de ervilhaca (Vicia spp). Pesq. Vet. Bras., v.21, p.162-171, 2001.

BREUKINK, H.H.; GRUYS, E.; HOLZHAUER, C. et al. Pyrexia with dermatitis in dairy cows. Vet. Rec., v.103, p.221, 1978.

FIGHERA, R.A.; BARROS, C.S.L. Systemic granulomatous disease in Brazilian cattle grazing pasture containing vetch (Vicia spp). Vet. Hum. Toxicol., v.46, p.62-66, 2004.

FIGHERA, R.A.; SOUZA, T.M.; BARROS, C.S.L. Lesões de pele em bovinos com doença granulomatosa sistêmica associada ao pastoreio de ervilhaca (Vicia spp.). Cienc. Rural, v.35, 406-411, 2005.

GAVA, A.; BARROS, C.S.L. Intoxicação por polpa cítrica. In: RIET, F.C.; SCHILD, A.L.; MÉNDEZ, M.C. Doenças de ruminantes $e$ equinos. São Paulo: Varela, 2001. p.212-215.

HARPER, P.A.; COOK, R.W.; GILL, P.A. et al. Vetch toxicosis in cattle grazing Vicia villosa spp., dasycarpa and V. benghalensis. Aust. Vet. J., v.70, p.140-144, 1993.

HEINRICHS, R.; FANCELLI, A.L. Influência do cultivo consorciado de aveia preta (Avena strigosa) e ervilhaca comum (Vicia sativa L.) na produção de fitomassa e no aporte de nitrogênio. Sci. Agric, v.56, p.27-32, 1999.
JOHNSON, B.; MOORE, J.; WOODS, L.W. et al. Systemic granulomatous disease in cattle in California associated with grazing hairy vetch (Vicia villosa). J. Vet. Diag. Investig., v.4, p.360362, 1992.

MATTHEWS, J.G.; SHREEVE, B. Pyrexia/ pruritis/haemorrhagic syndrome in dairy cows. Vet. Rec., v.103, p.408-409, 1978.

ODRIOZOLA, E.; PALOMA, E.; LOPEZ, T. et al. An outbreak of Vicia villosa (hairy vetch) poisoning in grazing Aberdeen Angus bulls in Argentina. Vet. Hum. Toxicol., v.33, p.278-280, 1991.

PANCIERA, R.J.; MOSIER, D.A.; RITCHEY, J.W. Hairy vetch (Vicia villosa Roth) poisoning in cattle: update and experimental induction of disease. J. Vet. Diag. Investig., v.4, p.318-325, 1992.

RECH, R.R.; FIGHERA, R.A.; OLIVEIRA, F.N. et. al. Meningoencefalite granulomatosa em bovinos em pastoreio de ervilhaca (Vicia spp.). Pesqui. Vet. Bras., v.23, p. 169-172, 2004.

RISSI, D.R.; RECK, R.R.; PIEREZAN, F. et al. Intoxicações por plantas e micotoxinas associadas a plantas em bovinos no Rio Grande do Sul: 461 casos. Pesq. Vet. Bras., v.27, p.261268, 2007. 